\title{
Congenital Left Mesenteric-Parietal Hernia Associated to a Small Bowel Volvulus: About a Case
}

\section{Coulibaly Yacaria*, Doumbia Aliou, Amadou Issa, Coulibaly Oumar Moussa, Kamaté Benoi, Djiré Mohamed Kassoum, Tanapo Kalifa}

Service of Pediatric Surgery, Teaching Hospital Gabriel Toure, Bamako, Mali

Email: ${ }^{\star}$ coulibalyyacak@yahoo.fr

How to cite this paper: Yacaria, C., Aliou, D., Issa, A., Moussa, C.O., Benoi, K., Kassoum, D.M. and Kalifa, T. (2020) Congenital Left Mesenteric-Parietal Hernia Associated to a Small Bowel Volvulus: About a Case. Open Journal of Pediatrics, 10, 404-410. https://doi.org/10.4236/ojped.2020.103041

Received: June 17, 2020

Accepted: July 12, 2020

Published: July 15, 2020

Copyright $\odot 2020$ by author(s) and Scientific Research Publishing Inc. This work is licensed under the Creative Commons Attribution International License (CC BY 4.0).

http://creativecommons.org/licenses/by/4.0/ (c) (i) Open Access

\begin{abstract}
Introduction: The left mesenterico-parietal hernia or left paraduodenal hernia is an anomaly of intestinal rotation which may be responsible for intestinal obstruction. It is rare. Observation: A 5-year-old boy was admitted for abdominal pain with episodes of vomiting and cessation of matters and gases. After clinical and paraclinical investigations, the diagnosis of occlusion was accepted and the child was operated. Exploration revealed a mesenterico-parietal hernia with a retrocolic sac measuring $11 \mathrm{~cm}$ of collar and a deep of $18 \mathrm{~cm}$ containing a twisted bowel. After reduction of the content, we untwisted the small intestine and released adhesions. The hernial sac was partially resected and the defect was closed. Operating outcomes were simple. Conclusion: The mesenterico-parietal hernia is a cause of organic intestinal obstruction. Although of congenital origin, it can have a late clinical manifestation. It should be considered in case of episodes of repetitive abdominal pain and vomiting to avoid complications.
\end{abstract}

\section{Keywords}

Mesenterico-Parietal Hernia, Small Bowel Volvulus, Child, Mali

\section{Introduction}

The left mesentero-parietal hernia, also called left paraduodenal hernia, is an exceptional form of intestinal rotation anomalies. It is the most common type of internal abdominal hernia. It represents $50 \%$ to $55 \%$ of all intestinal hernias. In addition, $80 \%$ of them would be observed on the left side [1]. The occlusion mechanism is an intestinal fold at the hernial neck, without ischemia [2]. Most 
often, its clinical picture is a digestive symptomatology with a type of incomplete high occlusion usually recurrent. This symptomatology can continue during a few months, even a few years and up to childhood in certain cases thus favoring a diagnostic wandering with risks of complications. In all cases, despite the potential seriousness of these complications, the prognosis remains better due to the localized nature of intestinal ischemia. We report a case of mesenterico-parietal hernia associated with non-ischemic small bowel volvulus.

\section{Observation}

A 5-year-old boy, admitted for sudden onset of abdominal pain associated with bilious vomiting, matters and gases cessation, lasting for 4 days before his admission. In his history, he was born at term with a birth weight of $2500 \mathrm{~g}$, an apgar of 10 . He had since the age of 6 months episodes of abdominal bloating, crying, profuse diarrhea and food vomiting. No diagnosis was made after several medical visits to the pediatrician. In admission he a growth retardation, a good conscience, well-colored conjunctiva, hemodynamic and respiratory stability, a body weight of $14 \mathrm{~kg}$, a $\mathrm{Z}$ score of -2 , a temperature of $37.5^{\circ} \mathrm{C}$. His abdomen was distended, with a tympanism. The rectal ampoule was empty on digital rectal examination. A Plan abdominal radiograph revealed mixed-type hydro-aeric levels (small intestinal, colic) with absence of rectal air (Figure 1). A biological assessment was carried out. The hemoglobin level was $12 \mathrm{~g} / \mathrm{dl}$, the hematocrit at 36 , the white blood cells at 4000, the platelets at 150,000, the natremia at 120 $\mathrm{mmol} / \mathrm{L}$, the serum potassium at $2 \mathrm{mmol} / \mathrm{L}$, the chloremia at $98 \mathrm{mmol} / \mathrm{L}$ and

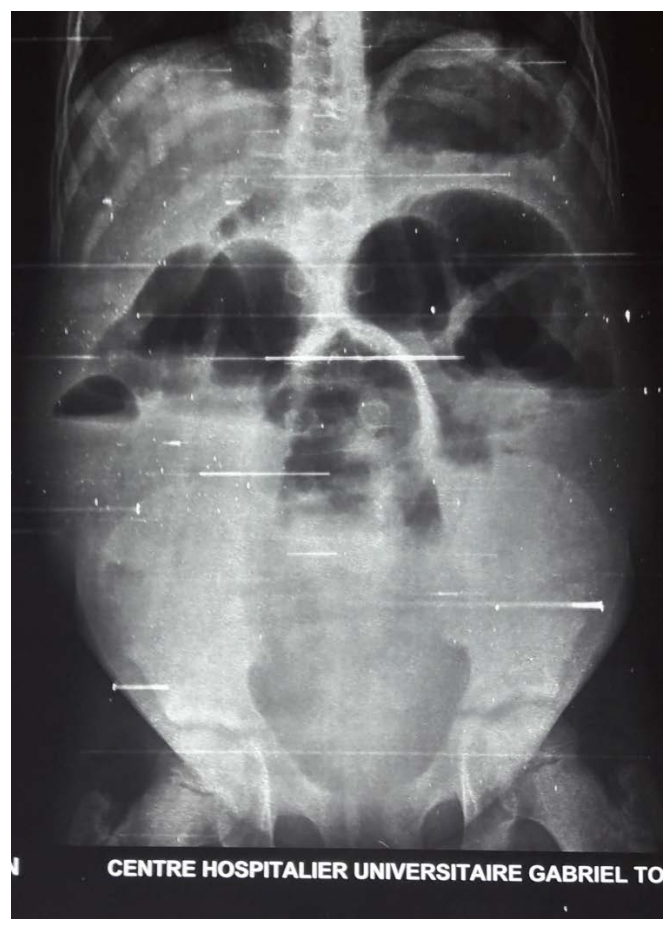

Figure 1. Plan abdominal radiograph showing hydroaeric levels with no air in the rectum. 
calcemia at $2.25 \mathrm{mmol} / \mathrm{L}$, urea at $3 \mathrm{mmol} / \mathrm{L}$ and creatinemia at $60 \mu \mathrm{mol} / \mathrm{L}$. Because of this clinical picture, the diagnosis of intestinal volvulus was retained and the patient was prepared for surgery. The intervention was carried out after 4 hours of resuscitation. During surgical exploration, a paraduodenal and retrocolic hernial sac (Figure 2) with intestinal contents was noted. After a reduction of hernial content, we have found a hernial sac with a collar of $11 \mathrm{~cm}$ and a deep of $18 \mathrm{~cm}$ (Figure 3). There was a small bowel volvulus with ileo-ileal bands (Figure 4). We untwisted the small intestine and released adhesions. The hernial sac was partially resected and closed. The operating outcome was simple. Intestinal transit resumed on D2 postoperatively. The child was discharged from the hospital on D5.

\section{Discussion}

Peritoneal recesses are usually related to rotation of the gut and adhesion of abdominal viscera to the posterior abdominal wall during fetal development, and/or the presence of retroperitoneal vessels which raise serosal folds [3].

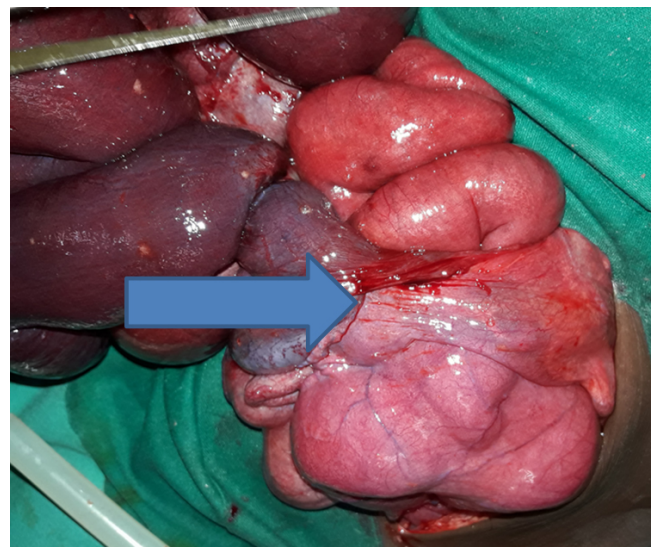

Figure 2. Hernial sac contening small bowel.

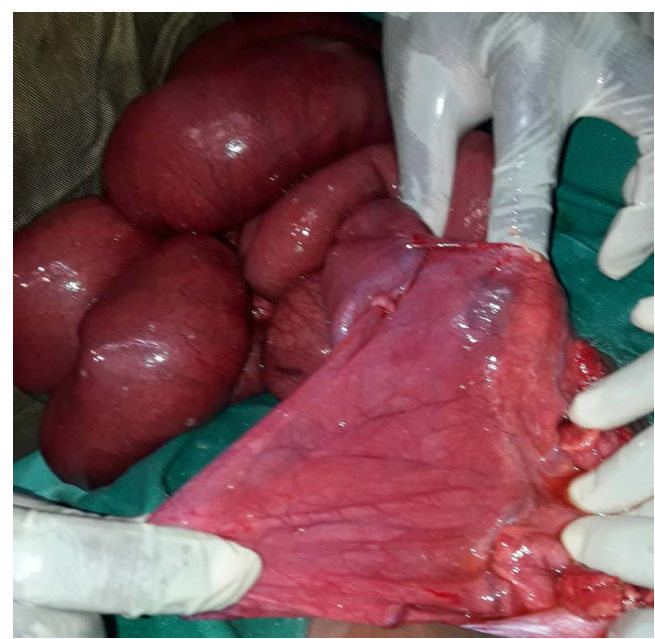

Figure 3. Retrocolic hernia sac with a collar of 11 $\mathrm{cm}$ and a deep of $18 \mathrm{~cm}$. 


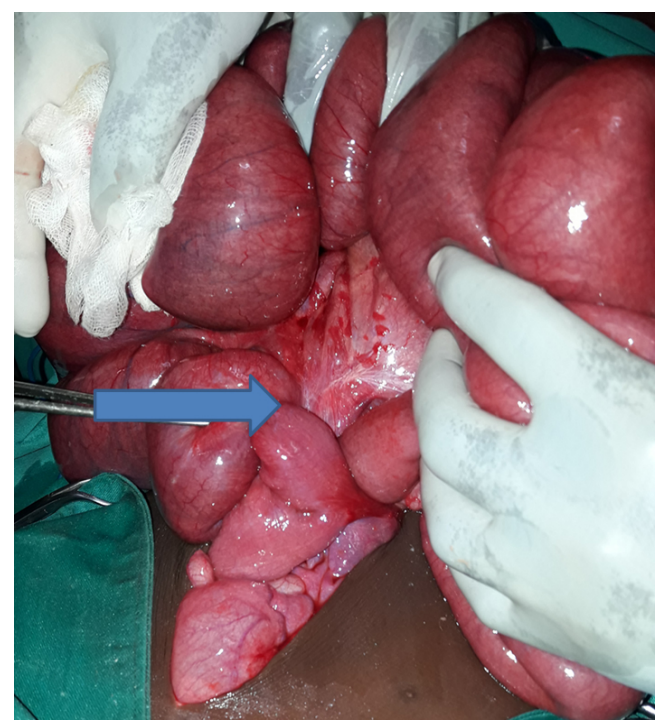

Figure 4. Perioperative image of small intestinal volvulus.

Due to the complex nature of the rotation of the gut and resorption of the mesentery, these recesses may enlarge or recede, and individual variations may lead to the development of different recesses in this area. Paraduodenal fossa originates as congenital peritoneal anomaly owing to failure of mesenteric fusion with the parietal peritoneum. There is also an associated abnormal rotation during imprisonment of the small intestine beneath the developing colon. These recesses, therefore, are regarded as congenital and have been considered clinically and surgically as sites for internal abdominal hernias [4]. Para duodenal hernia is the most common cause of internal hernia. It represents alone $53 \%$ of internal hernias and $75 \%$ of para-duodenal hernias [5]. The left mesenterico-parietal or paraduodenal hernia is the protrusion of the intra-abdominal viscera through the Landzert paraduodenal fossa [6]. According to some authors, they interest men three times more often than women [7] [8]. Our case was also discovered in a boy.

These hernias are difficult to diagnose clinically. Internal hernia can be asymptomatic or cause significant discomfort ranging from constant vague epigastric pain to intermittent colicky periumbilical pain [9]. Additional symptoms include nausea, vomiting and recurrent intestinal pain. In the history of our patient, we noted notions of repeated abdominal pain, notions of vomiting and diarrhea and a growth retardation with a $\mathrm{Z}$ score of -2 . The frank occlusion picture was clear only at his 5 th year of life.

Imaging studies often play an important role in the diagnosis of internal hernias. General radiographic features with barium studies include apparent encapsulation of distended bowel loops with an abnormal location, arrangement or crowding of small bowel loops within the hernia sac. In our patient, because of emergency a plan abdominal radiograph was performed and revealed several mixed air-fluid levels and an absence of air in the rectum which did not suggest 
an internal hernia. The upper intestinal transit was not carried out.

Today CT has become the first-line imaging technique in this pathology. On CT finding include mesenteric vessel abnormalities with engorgement, crowding, twisting and stretching of these vessels and displacement of other bowel segment, especially the transverse colon, a sac-like mass of small bowel loops interposed between the stomach and pancreatic tall and a posterior mass effect on the stomach [10]. In our case, the computed tomography also was not carried out.

Ultrasonography has emerged as an important noninvasive method to evaluate the infant with emesis to exclude the diagnosis of pyloric stenosis. Additional information regarding the orientation of the superior mesenteric vessels also can be obtained by ultrasound and may be useful in suggesting the diagnosis of malrotation. In our case, ultrasound could have detected the volvulus of the small intestine associated with the hernia in the absence of abdominal distension.

Sometimes despite these meticulously performed radiologies the diagnosis remains uncertain and made intraoperatively [7] as was the case in our observation.

In an acutely ill child with midgut volvulus or obstruction, urgent operative correction is indicated and intravenous fluid resuscitation, placing a nasogastric tube and Foley catheter, typing and crossmatching blood, and giving broadspectrum antibiotics must be done concurrently and expeditiously. Time is critical in terms of intestinal salvage. Peroperatively, the diagnosis of mesenterico-parietal hernia can be difficult. It first requires the location of the hernial opening and an anatomical definition of the structural components. The hernial sac is retro-colonic. The collar is located between the duodeno-jejunal angle at the top and the inferior mesenteric artery at the bottom, while the free edge of the collar contains the inferior mesenteric vein and its identification also contributes to the diagnosis [2] [7].

In these hernias, in the majority of cases, the collar is wide and not very tight as in our observation, thus making it possible to obtain a complete reduction of its content by simple traction. In case of difficulties it may be useful to open it, but having in mind the vascular risk in his anterior lip. The hole in the dimple must then be closed without necessarily resecting the hernial sac. In complicated forms, the expansion and fragility of the handles are such that reduction may be impossible. Some authors have proposed the first detachment of the meso colon allowing the approach of the first sac with possibly prior emptying of the small intestine. It may be necessary to resect a sphaceled bowell [11].

The hernial opening must be closed using absorbable sutures or not. But any attempt to excise the hernial sac should be prohibited [7] [12] [13]. In our observation, the hernial sac was large enough and was partially resected.

The intestinal malrotation must be treated at the same time as in our observation. In the immediate postoperative period, the child did not face any concern. 
GI motility disturbances are common after operative correction of malrotation. Abnormalities characteristic of neuropathic pseudoobstruction raise the possibility of defective intrinsic enteric innervation. Further, the intestine may undergo reperfusion injury after reduction of a significant volvulus. Cytokines, bacteria, and other toxins may be released into the systemic circulation. This may contribute to hemodynamic instability during the intraoperative or early postoperative period.

\section{Conclusion}

Left para-duodenal hernia is a rare, but possible, cause of acute intestinal obstruction in children. This should be considered in the presence of spontaneously reduced episodes of sub-occlusion. Late diagnosis can cause complications such as loop necrosis.

\section{Parent Consent}

Due to the scientific interest of the case, the child's parents were informed and have given their consent for the publication.

\section{Conflicts of Interest}

The authors declare no conflicts of interest regarding the publication of this paper.

\section{References}

[1] Ghorbel, S., Chouikh, T., Chariag, A., Nouira, F., Khemakhem, R., Jlidi, S. and Chaouachi, B. (2011) Volvulus du Grêle associé à une hernie para duodénale gauche: A propos d'un cas. La Tunisie Médicale, 89, 192-195.

[2] Quenu, J., Loygue, J., Perrotin, J., Dubost, C. and Moreaux, J. (1967) Hernies rétro-duodénales. In: Opérations sur la paroi de l'abdomen et sur le tube digestif. Masson, Paris, 1147-1150.

[3] Alila, M., Marouni, A. and Toughrai, I. (2017) Hernie paraduodénale gauche: Une cause rare d'occlusion intestinale. Pan African Medical Journal, 28, 32. https://doi.org/10.11604/pamj.2017.28.32.13497

[4] Peltier, J., Gars, D.L., Page, C., Yzet, T. and Launde, M. (2005) The Duodenal Fossae Anatomic Study and Clinical Correlations. Surgical and Radiologic Anatomy, 27, 303-307. https://doi.org/10.1007/s00276-005-0332-9

[5] Régent, D., Ranchoup, Y., M’Benge, A., Nghi Phi, I., Chikhaoui, N. and Mathias, J. (2015) Imagerie radiologique des hernies internes. EMC-Radiologie et imagerie médicale-abdominale-digestive, 10, 1-24.

[6] Allabert, J., Andro, J.F., Charmouns, S., Teniere, P. and Testart, J. (1984) Les hernies para duodénales à propos de 2 cas. Annales de Chirurgie, 38, 50-53.

[7] Kotobi, H., Echaieb, A. and Gallot, D. (2005) Traitement chirurgical des hernies rares. EMC-Chirurgie, 2, 425-439. https://doi.org/10.1016/j.emcchi.2005.06.001

[8] Zissin, R., Hertz, M., Gayer, G., Paran, H. and Osadchy, A. (2005) Internal Hernia as a Cause of Small Bowel Obstruction: CT Findings in 11 Adult Patients. BJR, 78, 796-802. https://doi.org/10.1259/bjr/87050272 
[9] Ghahremani, G.G. (2000) Abdominal and Pelvic Hernias. In: Gore, R.M. and Levine, M.S., Eds., Texbook of Gastrointestinal Radiology, $2^{\text {nd }}$ Edition. Saunders, Philadelphia, PA, 1993-2009.

[10] Blachar, A., Frederle, M.P. and Dodson, S.F. (2001) Internal Hernia: Clinical and Imaging Finding in 17 Patients with Emphasis on C Criteria. Radiology, 218, 68-74. https://doi.org/10.1148/radiology.218.1.r01ja5368

[11] Medarhri, J., El Ounani, M., Rachid, K., Jaafar, A., Iken, A., Echarrab, M., Elamraoui, M., Benchekroun, A. and Balafrej, S. (1997) Hernie interne para-duodénale gauche à propos d'une nouvelle observation. Médecine du Maghreb, 62, 20-22.

[12] Finck, C.M., Barker, S., Simon, H. and Marx, W. (2000) A Novel Diagnosis of Left Paraduodenal Hernia through Laparoscopy. Surgical Endoscopy, 14, 87.

[13] Gupta, S., Singh, O., Hastir, A. and Sabharwal, G. (2010) Left Paraduodenal Hernia Causing Acute Small Bowel Obstruction. Arab Journal of Gastroenterology, 11, 50-52. https://doi.org/10.1016/j.ajg.2009.12.014 